\title{
Ruptured Brain Arteriovenous Malformations: Surgical Timing and Outcomes-A Retrospective Study of 25 Cases
}

\author{
Alessandro Di Bartolomeo ${ }^{1}$ Anthony Kevin Scafa ${ }^{1}$ Marco Giugliano ${ }^{1}$ Demo Eugenio Dugoni ${ }^{1}$ \\ Andrea Gennaro Ruggeri ${ }^{1}$ Roberto Delfini ${ }^{1}$ \\ 1Department of Neurological Sciences, Neurosurgery, “La Sapienza” \\ University of Rome, Rome, Italy \\ Address for correspondence Alessandro Di Bartolomeo, MD, \\ Department of Neurological Sciences, Neurosurgery, "La Sapienza" \\ University of Rome, 00161 Rome, Italy \\ (e-mail: diba.ale@gmail.com).
}

J Neurosci Rural Pract:2021;12:4-11

\begin{abstract}
Keywords

- cerebral hemorrhage

- ruptured brain

arteriovenous

malformation

- treatment

Background One important problem in treatment of ruptured brain arteriovenous malformations (bAVMs) is surgical timing. The aim of the study was to understand which parameters affect surgical timing and outcomes the most.

Materials and Methods Between January 2010 and December 2018, 25 patients underwent surgery for a ruptured bAVM at our institute. Intracerebral hemorrhage (ICH) score was used to evaluate hemorrhage severity, while Spetzler-Martin scale for AVM architecture. We divided patients in two groups: "early surgery" and "delayed surgery." The modified Rankin Scale (mRS) evaluated the outcomes.

Results Eleven patients were in the "early surgery" group: age $38 \pm 18$ years, Glasgow Coma Scale (GCS) $7.64 \pm 2.86$, ICH score $2.82 \pm 0.71$, hematoma volume $45.55 \pm$ $23.21 \mathrm{~mL}$. Infratentorial origin of hemorrhage was found in 27.3\% cases; AVM grades were I to II in $82 \%$, III in $9 \%$, and IV in $9 \%$ cases. Outcome at 3 months was favorable in $36.4 \%$ cases and in $54.5 \%$ after 1 year. Fourteen patients were in the "delayed surgery" group: age $41 \pm 16$ years, GCS $13.21 \pm 2.39$, ICH score $1.14 \pm 0.81$, hematoma volume $29.89 \pm 21.33 \mathrm{~mL}$. Infratentorial origin of hemorrhage was found in $14.2 \%$ cases; AVM grades were I to II in $50 \%$ and III in $50 \%$. Outcome at 3 months was favorable in $78.6 \%$ cases and in $92.8 \%$ after 1 year.

Conclusions The early outcome is influenced more by the ICH score, while the delayed outcome by Spetzler-Martin grading. These results suggest that it is better to perform surgery after a rest period, away from the hemorrhage when possible. Moreover, this study suggests how in young patient with a high ICH score and a low AVM grade, early surgery seems to be a valid and feasible therapeutic strategy.
\end{abstract}

\section{Introduction}

Arteriovenous malformations (AVMs) constitute a specific subgroup of lesions that can affect each structure of the brain, with a prevalence between 70 and $93 \%$ at the level of supratentorial structures. ${ }^{1}$ They consist of an anomalous tangle of modified, high-flow vessels characterized by the shunting of arterial blood into draining veins in the absence of a physiological capillary bed. The average reported detection rate for this condition is 1.34 per 100,000 person-years. ${ }^{2}$
DOI https://doi.org/ 10.1055/s-0040-1716792 ISSN 0976-3147. (c) 2020. Association for Helping Neurosurgical Sick People.

This is an open access article published by Thieme under the terms of the Creative Commons Attribution-NonDerivative-NonCommercial-License, permitting copying and reproduction so long as the original work is given appropriate credit. Contents may not be used for commercial purposes, or adapted, remixed, transformed or built upon. (https://creativecommons.org/licenses/by-nc-nd/4.0/)

Thieme Medical and Scientific Publishers Pvt. Ltd. A-12, 2nd Floor, Sector 2, Noida-201301 UP, India 
Although AVMs can be silent for many years, in more than $50 \%$ of the cases clinical onset occurs with hemorrhage. ${ }^{2}$ About $2 \%$ of all intracranial hemorrhage is due to rupture of a brain arteriovenous malformation (bAVM). AVM-related hemorrhage results in varying degrees in morbidity with a risk of permanent neurological deficits of 30 to $50 \%$ and mortality of 10 to $30 \%{ }^{3}$ Current literature data show that AVM rupture is associated with a risk of rebleeding ranging from 6 to 39\% per year following the initial hemorrhage.-6

While definitive treatment is fairly standardized, ${ }^{7}$ surgical timing in case of ruptured bAVM is less standardized. International literature ${ }^{2,8-10}$ recommends, in general, a variable "rest period" (1-6 weeks) between the hemorrhage and the conclusive treatment.

The aim of the study was to clarify, through a retrospective analysis of a multioperator series, (1) which parameters should be considered in the choice of the best surgical timing in case of ruptured bAVMs and (2) how these parameters can influence outcomes.

\section{Materials and Methods}

Between January 2010 and June 2018, 32 patients affected by bAVMs underwent surgery in the Neurosurgery Department of Sapienza University of Rome. Of these, 25 met the inclusion criteria (radiological evidence of intracranial hemorrhage) and were therefore analyzed.

For each patient we evaluated: age, sex, pre-existing medical comorbidities, onset symptoms and signs, discharge symptoms and signs, angioarchitectural characteristics of the lesion (including size, location, and venous drainage), bleeding severity, treatment modalities, surgical timing, and outcomes at 3 and 12 months. AVMs were investigated using computed tomography angiography, magnetic resonance imaging angiography, and/or traditional angiography. The Spetzler-Martin AVM grading system was applied to the classification of the lesions. ${ }^{11}$ The presence or absence of aneurysms on feeding arteries was also taken into account. Risk stratification, in relation to bleeding severity, was evaluated through the use of intracerebral hemorrhage (ICH) score that takes into consideration: (1) Glasgow Coma Scale (GCS), (2) hematoma volume (mL), (3) infratentorial origin (yes/no), (3) intraventricular hemorrhage (IVH) (yes/no), and (4) age (years). Regarding surgical timing, we divided patients into two groups: (1) "early surgery" (timing $\leq 48$ hours, 11 patients) and (2) "delayed surgery" (timing $>48$ hours, 14 patients). In each case, histological examination confirmed the diagnosis of AVM.

ICH score and time of surgery for each patient are showed in - Table 1.

We employed the modified Rankin Scale (mRS) to assess outcomes in terms of degree of disability/dependence following the acute event. ${ }^{12}$

Univariate and multivariate analysis of the collected data were performed using Excel, MATLAB and Stata. For each parameter, we calculated mean and standard deviation. We also estimated correlation, covariance, and relation coefficient with the ordinary least squares (OLS) linear regression model.
Table 1 Results of the cohort analysis

\begin{tabular}{|c|c|}
\hline Age & No. of patients \\
\hline $\begin{array}{l}<40 y \\
\geq 40 y\end{array}$ & $\begin{array}{l}11 \\
14\end{array}$ \\
\hline \multicolumn{2}{|l|}{ Sex } \\
\hline $\begin{array}{l}\text { Male } \\
\text { Female }\end{array}$ & $\begin{array}{l}8 \\
17\end{array}$ \\
\hline \multicolumn{2}{|l|}{ GCS } \\
\hline $\begin{array}{l}\text { GCS } \geq 14 \\
\text { GCS } 9-13 \\
\text { GCS } \leq 8\end{array}$ & $\begin{array}{l}11 \\
6 \\
8\end{array}$ \\
\hline \multicolumn{2}{|l|}{ Hemorrhage location } \\
\hline $\begin{array}{l}\text { Typical location } \\
\text { Atypical location }\end{array}$ & $\begin{array}{l}5 \\
20\end{array}$ \\
\hline \multicolumn{2}{|l|}{ Presence of intraventricular hemorrhage } \\
\hline $\begin{array}{l}\text { Yes } \\
\text { No }\end{array}$ & $\begin{array}{l}11 \\
14 \\
\end{array}$ \\
\hline \multicolumn{2}{|l|}{$\mathrm{ICH}$ volume } \\
\hline $\begin{array}{l}<30 \mathrm{~mL} \\
>30 \mathrm{~mL}\end{array}$ & $\begin{array}{l}12 \\
13\end{array}$ \\
\hline \multicolumn{2}{|l|}{ Supra/infratentorial hemorrhage } \\
\hline $\begin{array}{l}\text { Supratentorial } \\
\text { Infratentorial }\end{array}$ & $\begin{array}{l}20 \\
5\end{array}$ \\
\hline \multicolumn{2}{|l|}{ Spetzler-Martin grade } \\
\hline $\begin{array}{l}\text { I or II (Spetzler-Ponce class A) } \\
\text { III (Spetzler-Ponce class B) } \\
\text { IV (Spetzler-Ponce class C) }\end{array}$ & $\begin{array}{l}16 \\
8 \\
1\end{array}$ \\
\hline \multicolumn{2}{|l|}{ Presence of AVM-related aneurysms } \\
\hline $\begin{array}{l}\text { Yes } \\
\text { No }\end{array}$ & $\begin{array}{l}7 \\
18\end{array}$ \\
\hline \multicolumn{2}{|l|}{ Surgical timing } \\
\hline $\begin{array}{l}\text { Timing } \leq 48 \mathrm{~h} \\
\text { Timing } \geq 48 \mathrm{~h}\end{array}$ & $\begin{array}{l}11 \\
14\end{array}$ \\
\hline \multicolumn{2}{|l|}{ Treatment modalities } \\
\hline $\begin{array}{l}\text { Grade I-II } \\
\text { Surgery (microsurgical resection) } \\
\text { Only evacuation of hematoma }\end{array}$ & $\begin{array}{l}15 \\
1\end{array}$ \\
\hline $\begin{array}{l}\text { Grade III } \\
\text { Surgery (microsurgical resection) } \\
\text { Multimodal (endovascular and surgical) } \\
\text { treatment }\end{array}$ & $\begin{array}{l}1 \\
7\end{array}$ \\
\hline $\begin{array}{l}\text { Grade IV } \\
\text { Only evacuation of hematoma }\end{array}$ & 1 \\
\hline \multicolumn{2}{|l|}{ Outcomes } \\
\hline Mortality & 3 \\
\hline $\begin{array}{l}\mathrm{mRS} \text { at } 3 \mathrm{mo} \\
\text { favorable }(\mathrm{mRS} \leq 2) \\
\text { unfavorable }(\mathrm{mRS} \geq 3)\end{array}$ & $\begin{array}{l}17 \\
8\end{array}$ \\
\hline $\begin{array}{l}\mathrm{mRS} \text { at } 1 \mathrm{y} \\
\text { favorable }(\mathrm{mRS} \leq 2) \\
\text { unfavorable }(\mathrm{mRS} \geq 3)\end{array}$ & $\begin{array}{l}19 \\
6\end{array}$ \\
\hline
\end{tabular}

Abbreviations: AVM, arteriovenous malformation; GCS, Glasgow Coma Scale; ICH, intracerebral hemorrhage; mRS, modified Rankin Scale. 
6 Ruptured bAVMs: Surgical Timing and Outcomes Di Bartolomeo et al.

Table 2 Surgical timing and ICH score (with its defining parameters: age, GCS, hematoma volume, infratentorial bleeding, and intraventricular hemorrhage)

\begin{tabular}{|c|c|c|c|c|c|c|c|}
\hline Patients & $\begin{array}{l}\text { Surgical } \\
\text { timing }\end{array}$ & $\begin{array}{l}\text { Age } \\
\text { (y) }\end{array}$ & GCS & $\begin{array}{l}\text { Hematoma } \\
\text { volume }(\mathrm{mL})\end{array}$ & $\begin{array}{l}\text { Infratentorial } \\
\text { hemorrhage }\end{array}$ & $\begin{array}{l}\text { Intraventricular } \\
\text { hemorrhage }\end{array}$ & ICH score \\
\hline Pt. 1 & $1 \mathrm{~h}$ & 24 & 8 & 41 & No & No & 2 \\
\hline Pt. 2 & $9 \mathrm{~h}$ & 9 & 8 & 12 & Yes & Yes & 4 \\
\hline Pt. 3 & $3 \mathrm{~h}$ & 22 & 12 & 62.5 & No & Yes & 3 \\
\hline Pt. 4 & $3 \mathrm{~h}$ & 23 & 4 & 55.3 & No & No & 3 \\
\hline Pt. 5 & $21 \mathrm{~h}$ & 40 & 12 & 89.4 & No & No & 2 \\
\hline Pt. 6 & $24 \mathrm{~h}$ & 80 & 10 & 42 & No & No & 3 \\
\hline Pt. 7 & $4 \mathrm{~h}$ & 43 & 3 & 10 & Yes & Yes & 4 \\
\hline Pt. 8 & $2 \mathrm{~h}$ & 17 & 7 & 57.5 & No & No & 2 \\
\hline Pt. 9 & $15 \mathrm{~h}$ & 40 & 5 & 13.86 & No & Yes & 2 \\
\hline Pt. 10 & $45 \mathrm{~h}$ & 77 & 6 & 75 & No & Yes & 3 \\
\hline Pt. 11 & $48 \mathrm{~h}$ & 44 & 9 & 42.5 & Yes & No & 3 \\
\hline Pt. 12 & $90 \mathrm{~d}$ & 43 & 14 & 32 & No & No & 1 \\
\hline Pt. 13 & $6 d$ & 22 & 6 & 16.4 & No & Yes & 2 \\
\hline Pt. 14 & $74 d$ & 40 & 13 & 45 & Yes & No & 2 \\
\hline Pt. 15 & $8 d$ & 23 & 11 & 24 & No & No & 1 \\
\hline Pt. 16 & $7 d$ & 29 & 15 & 24 & No & Yes & 1 \\
\hline Pt. 17 & $13 d$ & 43 & 11 & 60 & No & No & 2 \\
\hline Pt. 18 & $15 \mathrm{~d}$ & 69 & 14 & 13.5 & No & No & 0 \\
\hline Pt. 19 & $6 \mathrm{~d}$ & 57 & 14 & 46.62 & No & Yes & 2 \\
\hline Pt. 20 & $21 \mathrm{~d}$ & 32 & 15 & 13.4 & No & No & 0 \\
\hline Pt. 21 & $44 \mathrm{~d}$ & 62 & 14 & 24 & No & Yes & 1 \\
\hline Pt 22 & $9 \mathrm{~d}$ & 51 & 15 & 12.5 & No & No & 0 \\
\hline Pt. 23 & $8 \mathrm{~d}$ & 64 & 13 & 3 & Yes & Yes & 2 \\
\hline Pt. 24 & $53 \mathrm{~d}$ & 23 & 15 & 6.08 & No & No & 0 \\
\hline Pt. 25 & $6 \mathrm{~d}$ & 17 & 15 & 146.5 & No & Yes & 2 \\
\hline
\end{tabular}

Abbreviations: GCS, Glasgow Coma Scale; ICH, intracerebral hemorrhage.

\section{Results}

Results of the cohort analysis are described in $\boldsymbol{- T a b l e s} \mathbf{1}$ to $\mathbf{4}$, and in - Figs. 1 and 2 .

Trying to respond to our objectives, we focused our attention on the parameters analyzed below.

\section{ICH Score, Surgical Timing, and Outcome}

The mean ICH score for the "early surgery" subgroup of patients was $2.82 \pm 0.71$, while it was $1.14 \pm 0.81$ for the "delayed surgery" one. Patients with a favorable outcome $(\mathrm{mRS} \leq 2)$ at 3 months and 1 year had a mean ICH score, respectively, of $1.26 \pm 0.72$ and of $1.57 \pm 0.92$, while those with a poor outcome (mRS>2) at 3 months and 1 year had a mean ICH score respectively of $2.8 \pm 0.71$ and of $2.8 \pm 0.63$. We found a positive statistical correlation $(\rho)$ between bleeding severity and outcome, given the calculated values: 0.63 at 3 months and 0.50 at 1 year. Covariance ( $\sigma$ ) (ICH-score, mRS) at 3 months and 1 year was respectively 1.24 and 1.07 , both positive (the two values positively covary together).

Besides, through a linear regression model (OLS), we calculated the regression coefficient of the variable ICH score against mRS, obtaining these results: 0.91 at 3 months and
0.79 at 1 year. So, an increase in 1 unit of the ICH score implies an increase in the expected mRS score of 0.91 at 3 months and of 0.79 at 1 year ( - Figs. 3 and $\mathbf{4}$ ).

\section{Hematoma Volume, Surgical Timing, and Outcome}

In the "early surgery" subgroup, the average hematoma volume was $45.55 \pm 23.21 \mathrm{~mL}$, while in the "delayed surgery" subgroup was $29.89 \pm 21.33 \mathrm{~mL}$. As for the relationship between hematoma volume and outcome, patients with a volume $<30 \mathrm{~mL}$ (standard cut-off volume used for the evaluation of ICH severity ${ }^{13}$ ) had an average mRS of $2.09 \pm 1.13$ at 3 months and of $1.54 \pm 1.01$ at 1 year. In contrast, patients with a volume $>30 \mathrm{~mL}$ had an average $\mathrm{mRS}$ of $3.23 \pm 1.31$ at 3 months and of $2.38 \pm 1.91$ at 1 year.

We also calculated the regression coefficient of variables from here on (i.e., volume, age, GCS, infratentorial hemorrhage, IVH) in relation to outcome. We excluded ICH score, being this a synthesis of the other variables.

The following linear model was applied:

$$
\begin{aligned}
m R S= & \alpha+\hat{a}_{1} \text { Volume }+\hat{a}_{2} \text { age }+\hat{a}_{3} \text { GCS } \\
& +\hat{a}_{4} \text { infratent. hemor. } \\
& +\hat{a}_{5} \text { intraventr. hemor. }+\varepsilon
\end{aligned}
$$


Table 3 Spetzler-Martin grade and mRS at 3 months and 1 year

\begin{tabular}{|c|c|c|c|c|c|c|}
\hline Patients & $\begin{array}{l}\text { AVM diameter } \\
(\mathrm{cm})\end{array}$ & $\begin{array}{l}\text { Location } \\
\text { (eloquent or not } \\
\text { eloquent cortex) }\end{array}$ & Venous drainage & $\begin{array}{l}\text { Spetzler-Martin } \\
\text { grade }\end{array}$ & $\mathrm{mRS}$ at $3 \mathrm{mo}$ & $\mathrm{mRS}$ at $1 \mathrm{y}$ \\
\hline Pt. 1 & 1.5 & Eloquent & $\mathrm{S}$ & II & 2 & 1 \\
\hline Pt. 2 & 1.7 & Eloquent & $\mathrm{s}$ & II & 3 & 1 \\
\hline Pt.3 & 1.5 & Eloquent & $\mathrm{s}$ & II & 3 & 1 \\
\hline Pt. 4 & 2.5 & Not eloquent & $\mathrm{S}$ & 1 & 2 & 1 \\
\hline Pt. 5 & 2.6 & Eloquent & $\mathrm{S}$ & II & 4 & 3 \\
\hline Pt. 6 & 1.5 & Eloquent & $\mathrm{s}$ & II & 6 & 6 \\
\hline Pt. 7 & 1.7 & Eloquent & $\mathrm{S}$ & II & 6 & 6 \\
\hline Pt. 8 & 2.5 & Eloquent & $S$ and $D$ & II & 1 & 0 \\
\hline Pt. 9 & 2 & Eloquent & $S$ & III & 2 & 1 \\
\hline Pt. 10 & 3.5 & Eloquent & $\mathrm{D}$ & IV & 5 & 5 \\
\hline Pt 11 & 1 & Not eloquent & $\mathrm{D}$ & II & 6 & 6 \\
\hline Pt. 12 & 2.8 & Not eloquent & $\mathrm{s}$ & 1 & 2 & 1 \\
\hline Pt. 13 & 2.5 & Eloquent & $S$ & III & 3 & 2 \\
\hline Pt. 14 & 3.2 & Eloquent & $S$ & III & 4 & 3 \\
\hline Pt. 15 & 5 & Eloquent & $S$ & III & 1 & 1 \\
\hline Pt 16 & 1.3 & Not eloquent & $\mathrm{s}$ & 1 & 0 & 0 \\
\hline Pt. 17 & 2 & Eloquent & $\mathrm{S}$ & II & 3 & 2 \\
\hline Pt. 18 & 0.8 & Eloquent & $S$ & II & 2 & 1 \\
\hline Pt. 19 & 2.5 & Not eloquent & $\mathrm{s}$ & 1 & 2 & 1 \\
\hline Pt. 20 & 3.5 & Eloquent & $S$ & III & 2 & 1 \\
\hline Pt. 21 & 8 & Not eloquent & $\mathrm{s}$ & III & 1 & 1 \\
\hline Pt. 22 & 4 & Eloquent & $\mathrm{s}$ & III & 2 & 2 \\
\hline Pt. 23 & 3.5 & Not eloquent & $S$ and $D$ & III & 1 & 1 \\
\hline Pt. 24 & 1 & Not eloquent & $S$ & 1 & 1 & 1 \\
\hline Pt. 25 & 2.4 & Eloquent & $\mathrm{s}$ & $\|$ & 2 & 1 \\
\hline
\end{tabular}

Abbreviations: AVM, arteriovenous malformation; D, deep; mRS, modified Rankin Scale; S, superficial.

Table 4 Early postoperative complications in the early surgery and delayed surgery groups. The causes of death as an early complication in the early surgery subgroup were intracranial hypertension due to post-surgical hemorrhage or ischemia in two patients, pulmonary embolism in one patient. Only the difference in the mortality rates between the two subgroups was statistically significant $(p<0.05, \chi 2$-test)

\begin{tabular}{|l|l|l|}
\hline $\begin{array}{l}\text { Early postoperative } \\
\text { complications }\end{array}$ & $\begin{array}{l}\text { Early } \\
\text { surgery (\%) }\end{array}$ & $\begin{array}{l}\text { Delayed } \\
\text { surgery (\%) }\end{array}$ \\
\hline Neurological deficits & $36(4 \mathrm{pts})$ & $21(3 \mathrm{pts})$ \\
\hline Post-surgical hemorrhage & $18(2 \mathrm{pts})$ & $0(0 \mathrm{pts})$ \\
\hline Post-surgical ischemia & $9(1 \mathrm{pt})$ & $0(0 \mathrm{pts})$ \\
\hline Infection & $9(1 \mathrm{pt})$ & $0(0 \mathrm{pts})$ \\
\hline Seizures & $18(2 \mathrm{pts})$ & $7(1 \mathrm{pt})$ \\
\hline Pulmonary embolism & $9(1 \mathrm{pt})$ & $0(0 \mathrm{pts})$ \\
\hline Death & $27(3 \mathrm{pts})$ & $0(0 \mathrm{pts})$ \\
\hline
\end{tabular}

Regarding volume, we obtained the following coefficients: 0.02 at 3 months and 0.016 at 1 year, indicating that an increase in $1 \mathrm{~mL}$ in the hematoma volume relates to an

\section{Clinical presentations}

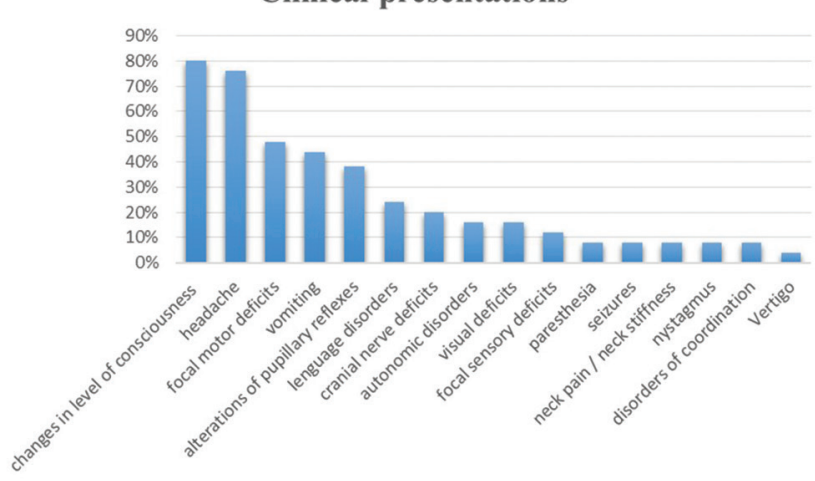

Fig. 1 Clinical presentations.

"expected" increase of 0.020 at 3 months and of 0.016 at 1 year in terms of mRS.

\section{GCS, Surgical Timing, and Outcome}

Patients in the "early surgery" subgroup had an average GCS of $7.64 \pm 2.86$, while those in the "delayed" one had an average GCS of $13.21 \pm 2.39$. 


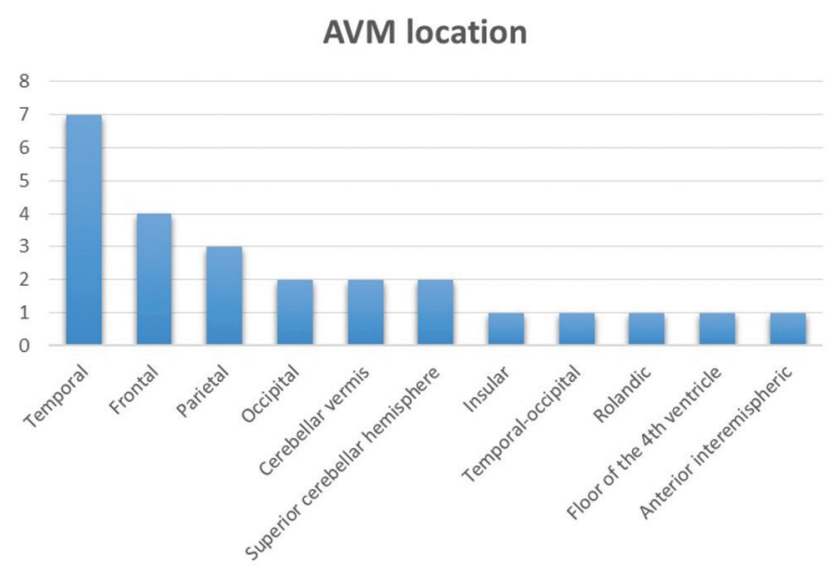

Fig. 2 Arteriovenous malformation (AVM) location.

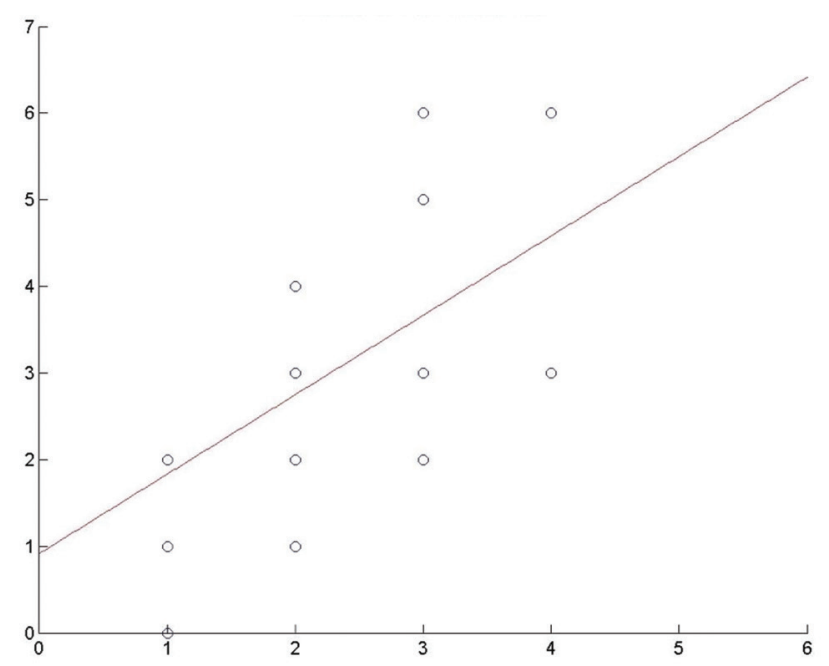

Fig. 3 Effect of intracerebral hemorrhage (ICH) score on modified Rankin Scale (mRS). Regression coefficient at 3 months.

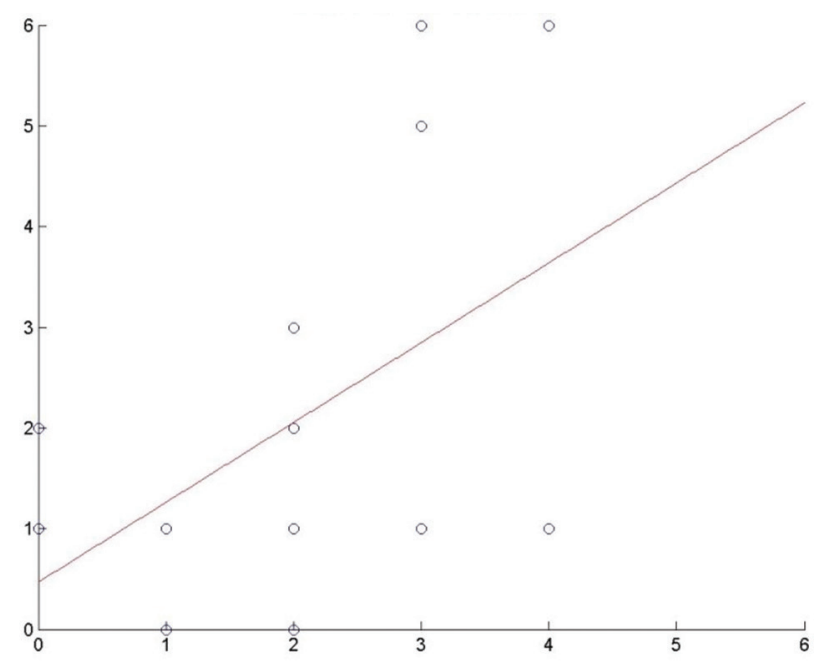

Fig. 4 Effect of intracerebral hemorrhage (ICH) score on modified Rankin Scale (mRS)s. Regression coefficient at 1 year.

As for the relationship between GCS and outcome, patients with a favorable mRS at 3 months had a debut average GCS of $11.93 \pm 3.11$ and those with a favorable mRS at 1 year had an average GCS of $11.36 \pm 3.80$. Patients with an unfavorable mRS at 3 months had an average GCS of $8.9 \pm 2,87$ and those with an unfavorable mRS at 1 year had an average GCS of $8.6 \pm 2,81$.

As described earlier, we also calculated for this variable regression coefficient against outcome with the following results: 0.196 at 3 months and 0.192 at 1 year, both negative. This means that an increase in 1 point in the GCS scale corresponds to a decrease of 0.196 at 3 months and of 0.192 at 1 year in terms of mRS.

\section{Infratentorial Origin of Hemorrhage, Surgical Timing, and Outcome}

Three patients (27.3\%) in the "early surgery" subgroup had an infratentorial hemorrhage at onset. In the "delayed surgery" subgroup infratentorial hemorrhage was present in two patients (14.2\%). Very interesting is the relationship with outcome. Patients with infratentorial bleeding presented an average $\mathrm{mRS}$ of $4 \pm 1.65$ at 3 months and of $3.4 \pm 2.05$ at 1 year. In contrast, patients without infratentorial hemorrhage presented an average mRS of $2.3 \pm 0.96$ at 3 months and of $1.6 \pm$ 0.77 at 1 year. We have also achieved a linear regression coefficient of the variable "infratentorial origin" in respect of $\mathrm{mRS}$ of 1.84 and 1.89 at 3 months and 1 year, respectively, both positive: this means that infratentorial origin of hemorrhage entails an expected increase in mRS of 1.84 at 3 months and of 1.89 at 1 year, that is a clear worsening of outcome.

\section{Presence of IVH, Surgical Timing, and Outcome}

The presence of IVH does not seem to have affected surgical timing, being present in five patients $(45.5 \%)$ in the "early surgery" subgroup and in six patients (42.82\%) in the "delayed surgery" one. Furthermore, the study of population in relation to this aspect did not allow us to obtain clear results about the correlation with outcome.

\section{Age, Surgical Timing, and Outcome}

The average age of patients in the two groups was $38 \pm$ 18 years in the "early surgery" subgroup and $41 \pm 16$ years in "delayed surgery" one: no statistically significant differences were, therefore, found. More interesting is the relationship between age and outcome. Patients aged $<40$ years had an average $\mathrm{mRS}$ of $2.14 \pm 1.12$ at 3 months and of $1.21 \pm 0.75$ at 1 year. Those aged $>40$ years had an average mRS of $3.27 \pm$ 1.73 at 3 months and of $2.9 \pm 1.65$ at 1 year. Even more interesting is the difference $\Delta(\mathrm{mRS})$ ( 1 year vs. 3 months) between the two populations which that $0.92 \pm 0.43$ in patients aged $<40$ years and $0.36 \pm 0.25$ in patients aged $>40$ years. This may suggest that the potentiality of outcome improvement is greater in younger patients. Also here, we calculated the regression coefficient of the variable "age" compared with mRS, obtaining the following results: 0.04 and 0.05 at 3 months and 1 year, respectively; this means that the 1 -year increase in age leads to an expected increase in mRS of 0.04 at 3 months and of 0.05 at 1 year. 
Spetzler-Martin Grade, Surgical Timing, and Outcome

Nine patients in the "early surgery" subgroup (82\%) harbored a Spetzler-Martingrade Ior IIAVM(class A). Only onepatient(9\%) had a grade III (class B) AVM. In the same way, only one patient (9\%) had a grade IV AVM. Regarding treatments, in the patient harboring grade IV (class C) AVM the only evacuation of the hemorrhage was performed, while in the patient with grade III (class B) AVM treatment was multimodal (i.e., endovascular embolization and microsurgery resection).

As for the "delayed surgery" subgroup, $50 \%$ of the patients harbored a grade I or II AVM (class A, 7 patients), while $50 \%$ had a grade III AVM (class B, 7 patients). All grade III lesions were subjected to presurgical endovascular embolization (multimodal treatment), though in one case it was not possible to complete the procedure.

To understand the existing link between Spetzler-Martin grading and patient outcomes, the most homogeneous subgroup, that is, the "delayed surgery" one (50\% grades I/II vs. $50 \%$ grade III), was selected; patients with class A AVM (grades I/II) had an average mRS of $1.71 \pm 0.63$ at 3 months and of $1 \pm 0.42$ at 1 year. Patients with class B AVM had an average $\mathrm{mRS}$ of $2 \pm 1.22$ at 3 months and of $1.56 \pm 0.62$ at 1 year. We also calculated the average ICH score of these two subgroups, and it was the same: $1.14 \pm 0.83$.

To identify the effect and the weight of the aforementioned parameters (Spetzler-Martin grade and ICH score) on outcomes, we used the same linear regression model applied above. Then we calculated the regression coefficient of both variables in relation to mRS, obtaining the following results: 0.44 for the ICH score and 0.29 for the SpetzlerMartin grade at 3 months; 0.25 for the ICH score and 0.57 for Spetzler-Martin grading at 1 year. This means that, even if in all cases the coefficients were positive and useful for the prediction of patient outcomes, mRS was most influenced by the ICH score (and so by the severity of hemorrhage) at 3 months; the situation was instead reversed at 1 year, being the outcome more influenced by Spetzler-Martin grade, and so by angioarchitectural AVM aspects and by their inherent surgical risk.

\section{Discussion}

Current neurosurgical literature still lacks randomized controlled trials ${ }^{14}$ showing that the benefits of the definitive treatment of bAVMs outweigh the risks. However, given that hemorrhage at diagnosis is one of the most relevant risk factors for subsequent new hemorrhage, ${ }^{3}$ definitive treatment is widely recommended, ${ }^{7,14-17}$ with the exception of those patients for which, because of the high surgical risk of the lesion (Spetzler-Ponce class C or Spetzler-Martin grades IV and $\mathrm{V}$ ), conservative management is recommended. ${ }^{16-18}$

The outcome of patients with ruptured bAVMs is generally favorable, with a mortality rate and a permanent disability rate relatively low compared with those of spontaneous intracerebral hemorrhage (sICH).

International literature ${ }^{2,7-10}$ recommends, in general, a "rest period" (1-6 weeks) between the hemorrhage and the conclusive treatment of the disease, since the risk of early rebleeding, though possible, is rare, and the "parenchyma" of the lesion can be "friable" in the period following the hemorrhage thus increasing surgical risk. It has been stated that this approach allows the safest surgical treatment (when this is indicated), also through a better diagnostic evaluation of the problem. However, when (1) significant mass effect is present, or (2) it is not possible to stabilize the patient and conservatively control intracranial and cerebral perfusion pressures, with subsequent progressive neurological deterioration, an urgent evacuation of the hematoma may be necessary. ${ }^{10,19}$ Management of this situation may also include the early resection of the AVM in the same single surgical time. AVM definitive treatment should be considered for those injures that are not expected to have a high surgical risk ${ }^{8}$; in this sense, there are also studies showing that this management is associated with a very favorable outcome. ${ }^{9}$

In our study, we found that, in case of hemorrhagic bAVMs, ICH score evaluation may be decisive in the choice of the best surgical timing. ICH score can also be one main predictive factor for patient outcome (in particular for early outcome), in accordance with Hemphill et al. ${ }^{20}$ This finding suggests that ICH score, scarcely used in presence of hemorrhagic bAVMs, can be a useful tool for both decision-making regarding therapeutic management, and outcome prediction, especially when considered along with two of the other characteristics examined, that is, age and Spetzler-Martin grade. ${ }^{21}$ The ICH score parameters that seemed to influence surgical timing the most were GCS and hematoma volume.

As far as outcomes are concerned, regression coefficients allowed us to detect a significant correlation with GCS, hematoma volume, and infratentorial origin.

It has been extremely interesting to note that while GCS and hematoma volume seem to affect especially early outcomes, the presence of an infratentorial hemorrhage affects both early and late outcomes. Infratentorial origin of the hemorrhage should, therefore, be considered in the decision-making about surgical timing. Moreover, also sICH guidelines emphasize that, in the presence of a cerebellar hemorrhage determining neurological deficits or hydrocephalus from IV ventricle obstruction, the early evacuation should be considered. ${ }^{22}$

Age deserves a separate discussion, as it is a variable that strongly influences outcomes.

Patients under 40 years of age had a significantly better outcome than patients older than 40 years. This parameter may explain why the outcome of patients affected by intracranial hemorrhage from ruptured BAVM is usually better than that of patients affected by primary $\mathrm{sICH}$, being these patients generally older. Accordingly, in a population-based study released in 2008, van Beijnum et al found that in case of AVM-related ICH, patients were younger, had a lower prestroke blood pressure, and a higher GCS at the entrance. They also were more likely to have an atypical ICH (lobar location) compared with patients affected by primary sICH. ${ }^{23}$

We have already argued about surgical risk determined by AVM characteristics. ${ }^{11,18,24}$

Certainly, also in our case, the grade of AVM influenced surgical timing. Nearly everyone within the "early surgery" 
group harbored a grade I or II AVM (Spetzler-Ponce class A), only one patient had a grade III and one patient a grade IV. Instead, 50\% of patients in the "delayed surgery" group presented a grade III AVM (Spetzler-Ponce class B). Grade III AVMs are injuries for which current literature recommends a careful angiographic assessment and multimodal treatment, wherever possible. ${ }^{18}$

In our study, early outcomes seem more influenced by the ICH score and therefore from hemorrhage severity, while delayed outcomes by Spetzler-Martin grading; this confirms the role of AVM angioarchitectural anatomy in the preoperative surgical risk assessment with the purpose to guide surgeons in the choice of the best treatment possible. ${ }^{16-18}$ It is, so, actually preferable (when possible) to intervene on the malformation away from the hemorrhage, to assess the best therapeutic strategy. ${ }^{16,17}$ According to Lawton et al, ${ }^{17}$ if a patient would have an additional benefit from embolization (provided that the risk is tolerable), double modality management appears indicated; of course, if the risk associated with embolization seems too high (e.g., in case of elevated intracranial pressure) only microsurgery should be done. Our analysis also showed that patients under 40 years of age with poor neurological status at the entrance, average ICH score of $2.67 \pm 0.62$, and low AVM surgical risk, undergoing early resection of the lesion, had a 3-month poor average mRS ( $2.47 \pm 0.71$ ), while at 1 year the outcome was very favorable $(1 \pm 0.4)$. This suggests, in line with other studies, ${ }^{9,18,25}$ how in young patients with a high ICH score at the entrance, one or more risk factors consistently related to poor outcome (low GCS, volume clot $>30 \mathrm{~mL}$, infratentorial hemorrhage), and a low-grade Spetzler-Martin malformation, early intervention of evacuation and AVM removal in one single surgical time represents a valid and feasible therapeutic strategy. In a study released in 2020, Deng et al reported a single-center study on 111 hemorrhagic bAVMs in children suggesting that early surgical treatment is preferable following the hemorrhagic presentation. ${ }^{25}$ Aboukaïs et $\mathrm{al}^{26}$ found that in grade I bAVMs long-term morbidity is, in the majority of cases, related to the brain damage determined by the hemorrhagic event; only in few cases, this may be linked to AVM resection.

Main limitations of this study are represented by the small cohort dimension, and by the retrospective fashion of the study.

\section{Conclusions}

When used together with Spetzler-Martin grading scale, ICH score seems to be a valid clinical instrument both in the management decision-making and in the outcome prediction in patients affected by hemorrhagic bAVMs. These parameters, considered together, allow a better evaluation about surgical timing, kind of treatment, and probable outcome.

Early outcomes seem to be more influenced by ICH score, and therefore by bleeding severity, delayed ones more by Spetzler-Martin grade, and so by AVM angioarchitecture. This suggests that it is indeed preferable, when possible, to intervene on the lesion itself after some time from the hemorrhage to evaluate the best treatment strategy.
Our study contributes to affirm the importance of an early treatment in patients affected by grade I or II bAVMs though with poor neurological status at the entrance. In fact, in young patients with a high ICH score at the entrance, one or more risk factors consistently related to poor outcome (low GCS, volume clot $>30 \mathrm{~mL}$, infratentorial hemorrhage), and a low-grade Spetzler-Martin malformation, early intervention of evacuation, and AVM removal in one single surgical time represent a valid and feasible therapeutic strategy. Confirmation of this will, of course, require further study and larger patient cohorts.

\section{Ethical Approval}

All procedures performed in studies involving human participants were in accordance with the ethical standards of the institutional and/or national research committee and with the 1964 Helsinki Declaration and its later amendments or comparable ethical standards. Informed consent was obtained from all individual participants included in the study.

\section{Funding \\ None.}

\section{Conflict of Interest}

None declared.

\section{References}

1 Laakso A, Dashti R, Juvela S, Niemelä M, Hernesniemi J. Natural history of arteriovenous malformations: presentation, risk of hemorrhage and mortality. Acta Neurochir Suppl (Wien) 2010;107:65-69

2 Ellenbogen RG, Abdulrauf SI, Sekhar LN, Principles of Neurosurgery. 3rd edition; 2012. Elsevier

3 Stapf C, Mast H, Sciacca RR, et al. Predictors of hemorrhage in patients with untreated brain arteriovenous malformation. Neurology 2006;66(9):1350-1355

4 Graf CJ, Perret GE, Torner JC. Bleeding from cerebral arteriovenous malformations as part of their natural history. J Neurosurg 1983;58(3):331-337

5 Mast H, Young WL, Koennecke HC, et al. Risk of spontaneous haemorrhage after diagnosis of cerebral arteriovenous malformation. Lancet 1997;350(9084):1065-1068

6 Forster DM, Steiner L, Håkanson S. Arteriovenous malformations of the brain. A long-term clinical study. J Neurosurg 1972;37(5):562-570

7 Ogilvy CS, Stieg PE, Awad I, et al; Special Writing Group of the Stroke Council, American Stroke Association. AHA Scientific Statement: recommendations for the management of intracranial arteriovenous malformations: a statement for healthcare professionals from a special writing group of the Stroke Council, American Stroke Association. Stroke 2001;32(6):1458-1471

8 Zacharia BE, Vaughan KA, Jacoby A. Hickman ZL, Bodmer D, Connolly ES Jr. Management of ruptured brain arteriovenous malformations. Curr Atheroscler Rep 2012;14(4):335-342

9 Kuhmonen J, Piippo A, Väärt K, et al. Early surgery for ruptured cerebral arteriovenous malformations. Acta Neurochir Suppl (Wien) 2005;94:111-114

10 Heros RC. Arteriovenous malformation-associated intracerebral hemorrhage. World Neurosurg 2012;78(6):586-587

11 Hamilton MG, Spetzler RF. The prospective application of a grading system for arteriovenous malformations. Neurosurgery 1994;34(1):2-6, discussion 6-7 
12 Wilson JT, Hareendran A, Hendry A, Potter J, Bone I, Muir KW. Reliability of the modified Rankin Scale across multiple raters: benefits of a structured interview. Stroke 2005;36(4): 777-781

13 Hemphill JC II, Greenberg SM, Anderson CS, et al; American Heart Association Stroke Council; Council on Cardiovascular and Stroke Nursing; Council on Clinical Cardiology. Guidelines for the management of spontaneous intracerebral hemorrhage: a guideline for healthcare professionals from the American Heart Association/American Stroke Association. Stroke 2015;46(7):2032-2060

14 Ross J, Al-Shahi Salman R. Interventions for treating brain arteriovenous malformations in adults. Cochrane Database Syst Rev 2010;(7):CD003436

15 Tuhrim S, Dambrosia JM, Price TR, et al. Intracerebral hemorrhage: external validation and extension of a model for prediction of 30-day survival. Ann Neurol 1991;29(6):658-663

16 Derdeyn CP, Zipfel GJ, Albuquerque FC, et al; American Heart Association Stroke Council. Management of brain arteriovenous malformations: a scientific statement for healthcare professionals from the American Heart Association/American Stroke Association. Stroke 2017;48(8):e200-e224

17 Lawton MT, Rutledge WC, Kim H, et al. Brain arteriovenous malformations. Nat Rev Dis Primers 2015;1:1500810.1038/ nrdp.2015.8

18 Spetzler RF, Ponce FA. A 3-tier classification of cerebral arteriovenous malformations. Clinical article. J Neurosurg 2011;114(3):842-849

19 Barr JC, Ogilvy CS. Selection of treatment modalities or observation of arteriovenous malformations. Neurosurg Clin N Am 2012;23(1):63-75
20 Hemphill JC II, Bonovich DC, Besmertis L, Manley GT, Johnston SC. The ICH score: a simple, reliable grading scale for intracerebral hemorrhage. Stroke 2001;32(4):891-897

21 Appelboom G, Hwang BY, Bruce SS, et al. Predicting outcome after arteriovenous malformation-associated intracerebral hemorrhage with the original ICH score. World Neurosurg 2012;78(6):646-650

22 Morgenstern LB, Hemphill JC III, Anderson C, et al; American Heart Association Stroke Council and Council on Cardiovascular Nursing. Guidelines for the management of spontaneous intracerebral hemorrhage: a guideline for healthcare professionals from the American Heart Association/American Stroke Association. Stroke 2010;41(9):2108-2129

23 van Beijnum J, Lovelock CE, Cordonnier C, Rothwell PM, Klijn CJM, Al-Shahi Salman R; SIVMS Steering Committee and the Oxford Vascular Study. Outcome after spontaneous and arteriovenous malformation-related intracerebral haemorrhage: population-based studies. Brain 2009;132(Pt 2): 537-543

24 Hartmann A, Pile-Spellman J, Stapf C, et al. Risk of endovascular treatment of brain arteriovenous malformations. Stroke 2002;33(7):1816-1820

25 Deng Z, Chen Y, Ma L, et al. Long-term outcomes and prognostic predictors of 111 pediatric hemorrhagic cerebral arteriovenous malformations after microsurgical resection: a single-center experience. Neurosurg Rev 2020;•••:10.1007/ s10143-019-01210-4

26 Aboukaïs R, Quidet M, Baroncini M, et al. Grade 1 Spetzler and Martin cerebral ruptured arteriovenous malformations treated by microsurgery: Poor functional outcome is related to injury from haemorrhage. Neurochirurgie 2017;63(2):69-73 